\title{
A modern day Corroboree: towards a history of the New South Wales Aboriginal Rugby League Knockout
}

\author{
Heidi Norman
}

\section{Introduction}

This paper presents a history of the Annual New South Wales Aboriginal Rugby League 'Knockout' Carnival, an annual football competition involving teams from all over the state. This significant event has been running for 36 years. For the New South Wales Aboriginal community, the Knockout is the biggest event of the year attracting up to 60 teams and many thousands of Aboriginal spectators. It is run by and for the Aboriginal community and is largely funded from private sponsorship and community support. For the most part this major sporting and cultural event goes unnoticed by the wider community, although the media coverage, particularly prevalent in regional centres reports the presence of Aboriginal people as an 'influx' and expresses fears over possible violence and disorder.

Much academic work in the field of Aboriginal history over the last 25 years has documented Indigenous peoples' resistance and political demands, such as Heather Goodall's ethnographic study of land in Aboriginal politics and Gillian Cowlishaw's studies of Aboriginal and non-Aboriginal race relations. ${ }^{1}$ Other works have sought to 'correct' earlier accounts of Australian history, such as the work of Reynolds. ${ }^{2}$ More recently Maria Nugent's study, Botany Bay, ${ }^{3}$ suggests a meeting of history and the place of remembering in historical renderings-a kind of multi-layered separate, but intersecting dialogue.

While these studies have been undertaken by non-Indigenous scholars, in various ways genuinely connected to the community and people who inform their study, the focus is inevitably about Aboriginal people 'on the margins'. We might see this in the studies of resistance to white domination and dispossession, in accounts of race relations or in the criss-crossing of experience and the different interpretations and meanings of events. By way of contrast, the challenge of my research is in part related to the nature of the event. The Knockout is an all-Aboriginal run, initiated and funded

1. Goodall 1996; Cowlishaw 2004, 2006.

2. Reynolds 1972, 1989, 1995.

3. Nugent 2005. 
event. Every aspect of this event speaks to Indigenous realities. In documenting this event perhaps a new account of Aboriginal history might be discerned in the context of self-determination, or at least a period 'more free' of the oppressive role of the Aborigines Welfare Board. The field of Aboriginal history necessarily hovers around black and white relations, while the focus of the study of this all-Aboriginal celebratory event is only briefly concerned with non-Aboriginal relations. But this is not to falsely elevate Indigeneity as a rarefied, separate reality, but rather to understand how this event emerged from particular experiences that are both culturally continuous in a traditional sense and historically produced.

The other related challenge that emerges is that this event has no precedent: in a scholarly sense as there are no previous studies, and in the sense that as a community event there have been no records or archives, aside from photos and media coverage of the Knockout. Therefore much of this study is based on primary research.

This article's main aim is to document an important and little known Aboriginal event that is significant for far more than its purely sporting connotations. The New South Wales Aboriginal Rugby League Knockout has been run independently since 1971 drawing on a range of private, government and community sponsorship. One aim of this essay is to make the simple point that a large number of Aboriginal people have been able to organise a hugely popular and complex event attended by many thousands of people over 36 years.

Besides providing a descriptive history of the Knockout, I want to show it as a different articulation of what might be thought of as political activism; how kinship and family relations are central to how we organise and how cultural practice and historical association interact in a dynamic process. The Knockout flowered from the complex interaction of economic change and its social impact, government policy and Aboriginal aspirations. This study, the first of its kind on the Knockout, seeks to locate this significant Aboriginal event in this historical context.

The football carnival can be understood as a modern and adapted medium for cultural performance and expression, for kinship-based modes of organisation merged with state shaped communities, and for courtship and competition. The football is reminiscent of a four-day traditional ceremonial dance and celebration, but also enables new social and cultural practices to emerge. It is an opportunity for families to gather, reunite as a community and barrack for their home-town and mob, and commemorate past glories and those who have passed on. The Knockout is fiercely contested; world class, tough football is on display.

The Knockout, beginning in Sydney in 1971, is widely described as a 'modern day Corroboree' and attracts teams from all over New South Wales from as far as Bourke, Moree, Dubbo, Ballina and Bega to the south. The event involves incredible organisation and planning, largely on a voluntary basis. Victory is cited as a lifetime highlight for players and communities.

\section{The history of the Knockout}

The Knockout emerged from the new and growing Sydney inner-city Aboriginal community in the late 1960 s and early 1970 s and can also be understood as part of a much 


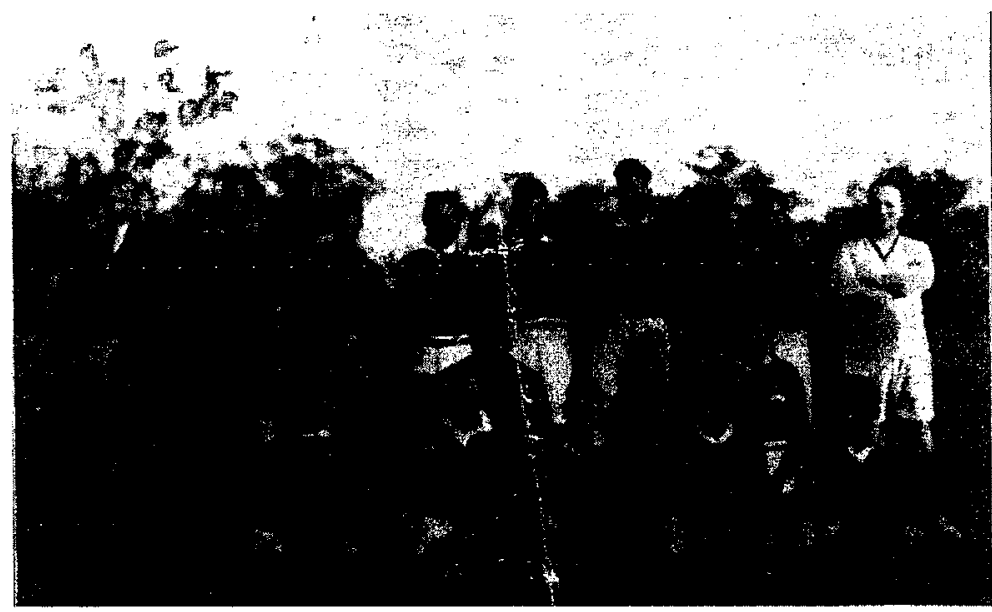

Moree

Boomerangs

1930s. Photo

reproduced

from a paper

copy held by

the Moree

Regional

Library

longer tradition of participation by Aboriginal people in the football code of Rugby League.

The changing relations between the state and Aboriginal people in New South Wales, such as the winding up of the Welfare Board and appointment of an Aboriginal advisory committee, created greater freedom for Aboriginal people to relocate to the city. The re-commitment to assimilation following the 1967 'Report of the NSW Parliamentary Joint Committee into Aborigines Welfare ${ }^{4}$ saw the devolution of responsibilities for Aboriginal related administration to departments such as Housing, and resulted in strategies to encourage 'chain relocation' of Aboriginal people from regional areas, especially the centralised missions or reserves, to urban areas with the promise of housing. 5

While the New South Wales Welfare Board had a controlling presence over the lives of Aboriginal people in regional centres through the reserves, the board did not have the same presence in the city. ${ }^{6}$ The emerging political movement in Redfern for self-determination and justice, increased opportunities arising from post-referendum federal government initiatives and greater employment prospects in the industrial areas of Sydney influenced Aboriginal families' migration to the inner-city, including Redfern and Alexandria.

The Knockout emerged within this complex economic and social context. It was initiated by six men affiliated with Koorie United: Bob Smith, Bob Morgan, Bill Kennedy, Danny Rose, Victor Wright and the late George Jackson. They formed Koorie United in response to the rapidly expanding Sydney Aboriginal community. The established Sydney-based Aboriginal sides, the Redfern All Blacks and La Perouse Blacks (or Panthers as they were sometimes called), were aligned with the South Sydney football district. There were many Aboriginal men looking for a game of football and so Koorie

4. The Report of the Joint Committee into Aborigines Welfare recommended abolishing the Welfare Board, that there be no new housing built on reserves and that the Government gradually divest itself of the Reserve lands.

5. Goodall 1995: 107.

6. For discussion of this, see Goodall 1995. 


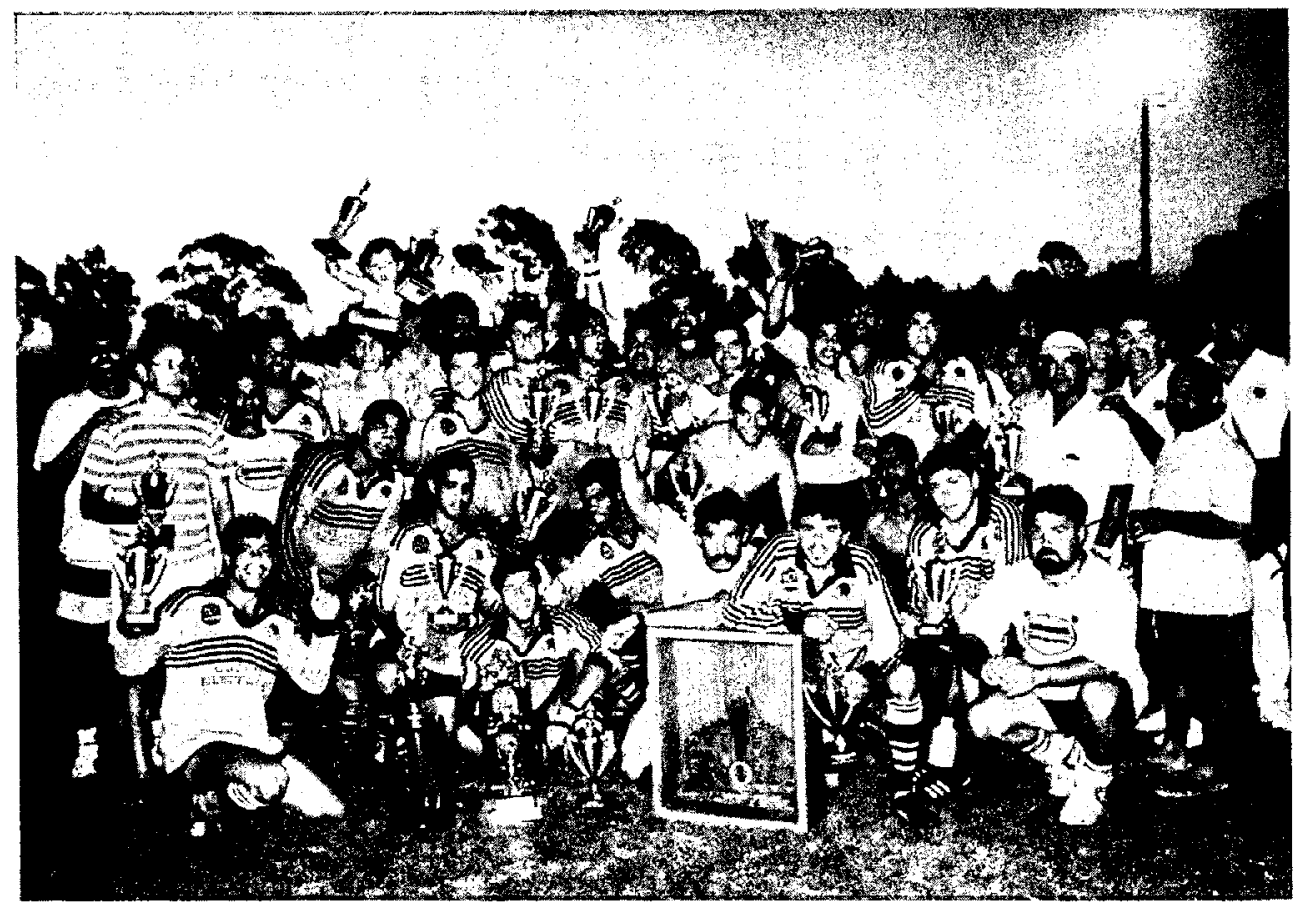

Above: The La Perouse Panthers, winners of the 1991 New South Wales Annual Aboriginal Rugby League Knockout. Photo reproduced with permission from Michael Lowe

Below: Redfern All Blacks, winners of the 2004 New South Wales Annual Rugby League Knockout. Photo by Heidi Norman

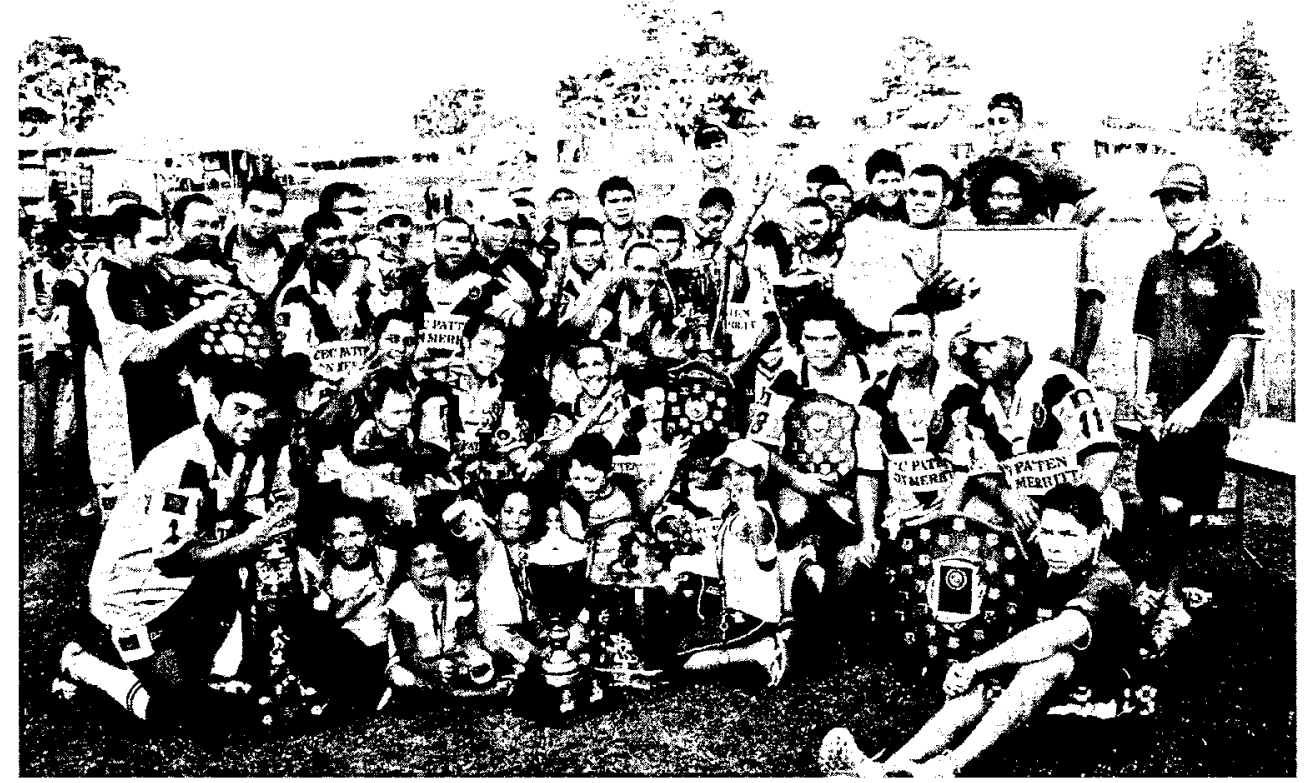


United formed joining the 'rival' Newtown Jets district, with sponsorship from Marrickville Council, where some of the committee members worked. The inaugural President was Jimmy Little. They emerged with something of a splash, taking out the premiership in $1970 .^{7}$

The Koorie United committee were connected through kinship and the shared experience of relocating to the city. Bob Morgan, Danny Rose and Bill Kennedy hail from the New South Wales north-western town of Walgett in Gamilaroi country. Bob Smith and Victor Wright had relocated from Kemspey on the New South Wales north coast, and while the late George Jackson was based in Sydney, he also had connections with Gamilaroi as his wife was from Coonabarabran. This kinship connection extended to Jimmy Little as his wife also hails from Walgett.

Following a meeting at the Clifton Hotel, a well-known gathering place for Kooris in Redfern in the 1960s, the Koorie United committee proposed holding a state-wide Knockout competition. Prior to this there had been many town-based knockout football and basketball competitions. However, the establishment of the Knockout set out with some different objectives. Bob Morgan says:

Our concept at the time was to also have a game where people who had difficulty breaking into the big time would be on show. They could put their skills on show and the talent scouts would come and check them out. ${ }^{8}$

The Knockout was formed with a view to providing a stage for the many and very talented Aboriginal footballers playing at the time who had been overlooked by the talent scouts. Although there were some notable exceptions, like Bruce (La Pa) Stewart playing on the wing for Easts, Aboriginal footballers experienced difficulty breaking into the 'big time'. It was thought the Knockout would provide a chance for Aboriginal footballers to get noticed, where for reasons of racism and lack of country-based recruitment they were overlooked. There was also some talk of entering an all-Aboriginal side in the National Rugby League competition.

Secondly, as original committee member Bob Morgan said:

The Knockout was never simply about football, it was about family, it was about community, it was getting people to come together and enjoy and celebrate things rather than win the competition football. ${ }^{9}$

This sentiment was echoed by most participants in this research. James Miller, former Koorie United player and Knockout supporter described the event in the following way: 'It's similar to Kooris getting together for funerals and weddings and things like this ${ }^{10}$ Bob Smith, founding member of the Knockout, expressing a similar sentiment said:

7. Jimmie Little was also a mad keen 'Balmain Tigers' supporter, so Koorie United began playing in his beloved Black and Gold!

8. Interview with B Morgan, conducted by the author, 30 May 2004, The Entrance, Central Coast.

9. Interview with B Morgan, conducted by the author, 30 May 2004, The Entrance, Central Coast.

10. Interview with J Miller, conducted by the author, 31 August 2004, Powerhouse Museum. 
It's almost got the same sort of feel about it, like when you go to funerals. It's not the same but it's still an opportunity for people to meet ... an opportunity for people to meet and renew friendships. ${ }^{11}$

The first Knockout in 1971, hosted by Koorie United at Camdenville Oval, St Peters, attracted seven teams: Koorie United, Redfern All Blacks, Kempsey, La Perouse, Walgett, Moree and a combined Mt Druitt / South Coast side.

For the first few years of the Knockout, Koorie United hosted the carnival and it was won by La Perouse United (1971), Redfern All Blacks (1972-73), Koorie United (1974) and Kempsey All Blacks in 1975. With Kempsey the first non-Sydney side to win the Knockout, it was decided that the winning team would host the Knockout the following year. The Kempsey Knockout was a memorial to the late Victor Wright Senior, a long time supporter of Aboriginal Football and the Knockout. The highly prized original trophy, donated by the Foundation for Aboriginal Affairs following a grant from the Commonwealth Council for Aboriginal Affairs, has the inscription 'NSW Koorie Sports Committee Annual Football Knockout "Perpetual Trophy", Donated by Foundation of Aboriginal Affairs'. After the 1975 Kempsey Knockout, the Victor Wright Senior Memorial Shield has continued as a perpetual trophy/shield awarded at the Knockout. ${ }^{12}$

In 2005, 35 years later, there were over 60 teams competing at the Knockout, hosted by the Redfern All Blacks Cec Patten - Ron Merritt Memorial Team. Bob Smith explained that in 1971 he hand-drew A4 cardboard signs and posted them around Redfern. The nomination fee was $\$ 5.00$ and the winner 'took all' of the $\$ 35$ prize money. In 2004 the entry fee was $\$ 2000$ and the winning team collected $\$ 60,000$ in prize money. There were also second, third and fourth place cash prizes. In addition, the women's Knockout that for a long time was a side event, in 2005 attracted 22 teams with the crowd-pleasing final played on the Monday of the long weekend.

Aside from Sydney, it has been hosted in the rural towns of Dubbo, Armidale, Bourke, Walgett and Moree and in the coastal communities of Kempsey, Maitland and Nambucca Heads.

\section{Aboriginal people and Rugby League}

The history of the Knockout and its formation in 1971 drew on existing involvement in the code of rugby league by Aboriginal people. All of the passion and success of the Knockout is continuous with this longer history. There were several all-Aboriginal rugby league sides in New South Wales that were competing in city and country competitions as early as the 1930s. Including the Redfern All Blacks and La Perouse Blacks / Warriors in the Souths Juniors competition, the Erambie All Blacks from Cowra, the Waratahs based in Dubbo, the Moree Boomerangs, a team from Bellbrook Mission in the Kempsey Valley and the Foster Hawkes - winners of the Manning Valley - Great Lakes Premierships in the 1930s, from Sunrise Station (later known as Purfleet Mission).

11. Interview with B Smith, conducted by the author, 19 September 2004, Offices of the Department of Education, Kempsey.

12. Over the 35 years of the Knockout some 35 commemorative perpetual trophies and shields have been added, including the Gamilaroi Elders Shield in 2002. 


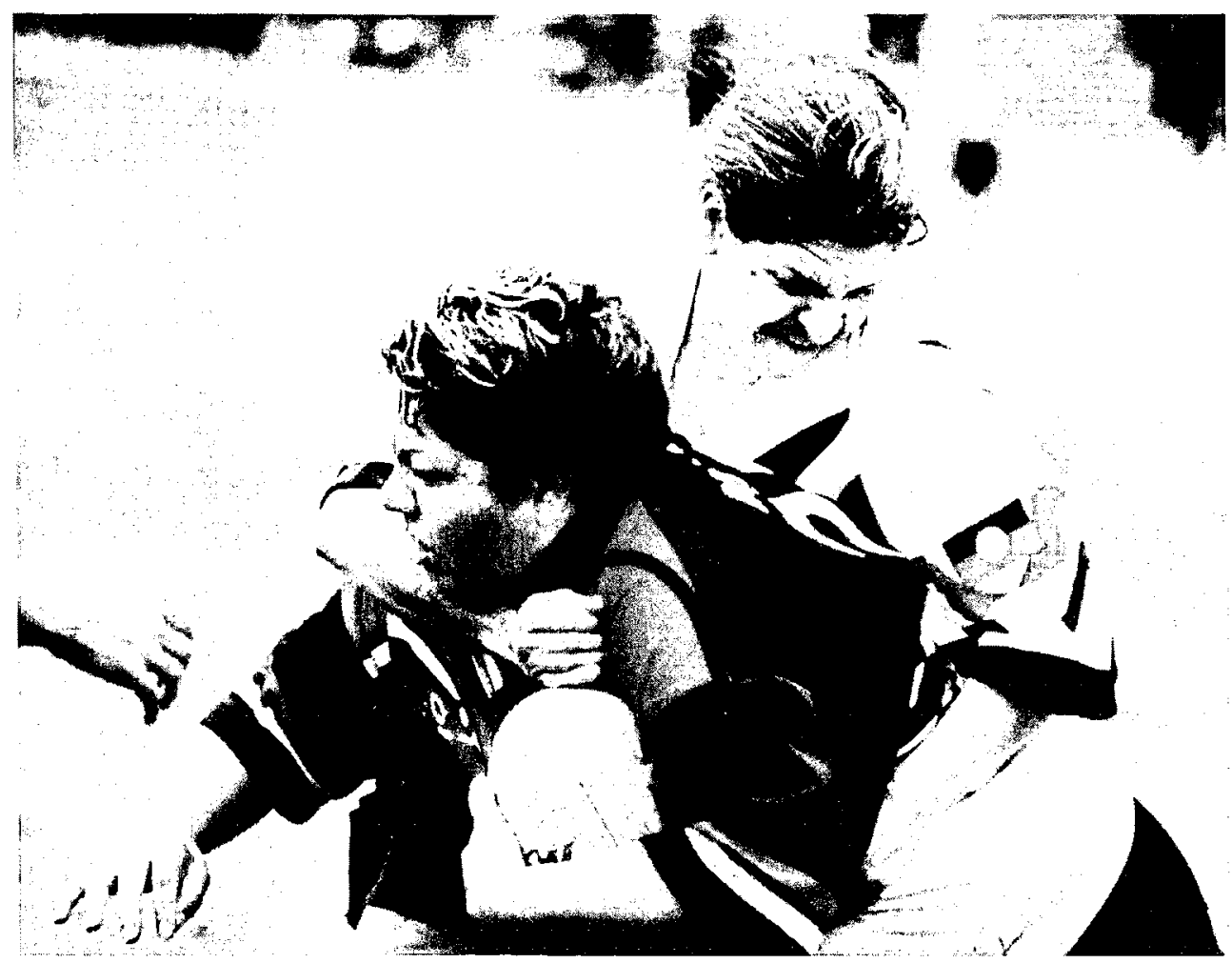

2003 Annual Aboriginal Rugby League Knockout, Maitland. Photo courtesy Koori Mail.

Colin Tatz argues that Rugby League has been 'kinder to Aborigines than any other football code'. ${ }^{13}$ Aboriginal men are well represented in rugby league. Tatz suggests George Green was the first Aboriginal player competing in the Premiership playing with Eastern Suburbs in 1911 and later the North Sydney 'glory team' premiership winners in 1921 and 1922. Tatz calculated that in the senior Sydney premiership competition in 1987, there were between 29 and 32 Aboriginal players, making up $9 \%$ of the players in premier and reserve grade sides. ${ }^{14}$ In the 2005 National Rugby League Grand Final, it was reported that Indigenous Australians 'will make up more than $20 \%$ of the players who will run onto the field at Telstra Stadium'. ${ }^{15}$ Perhaps this success can be attributed to the origins of the game having split from Rugby Union in the early 1900s, Rugby League came to be a sport of the working class. The South Sydney Rabbitohs, from the working class areas of Redfern were one of the foundation clubs and dominated the premiership in the early years. ${ }^{16}$

The Redfern All Blacks (RAB), who celebrated their 75th Anniversary in November 2005, has been central to the social, cultural and political history of Aboriginal

\footnotetext{
13. Tatz 1995: 10.

14. Tatz 1995: chapter 8.

15. Sydney Morning Herald, Weekend Edition, 1-2 October 2005: 7.

16. These tentative ideas will be developed in further work.
} 


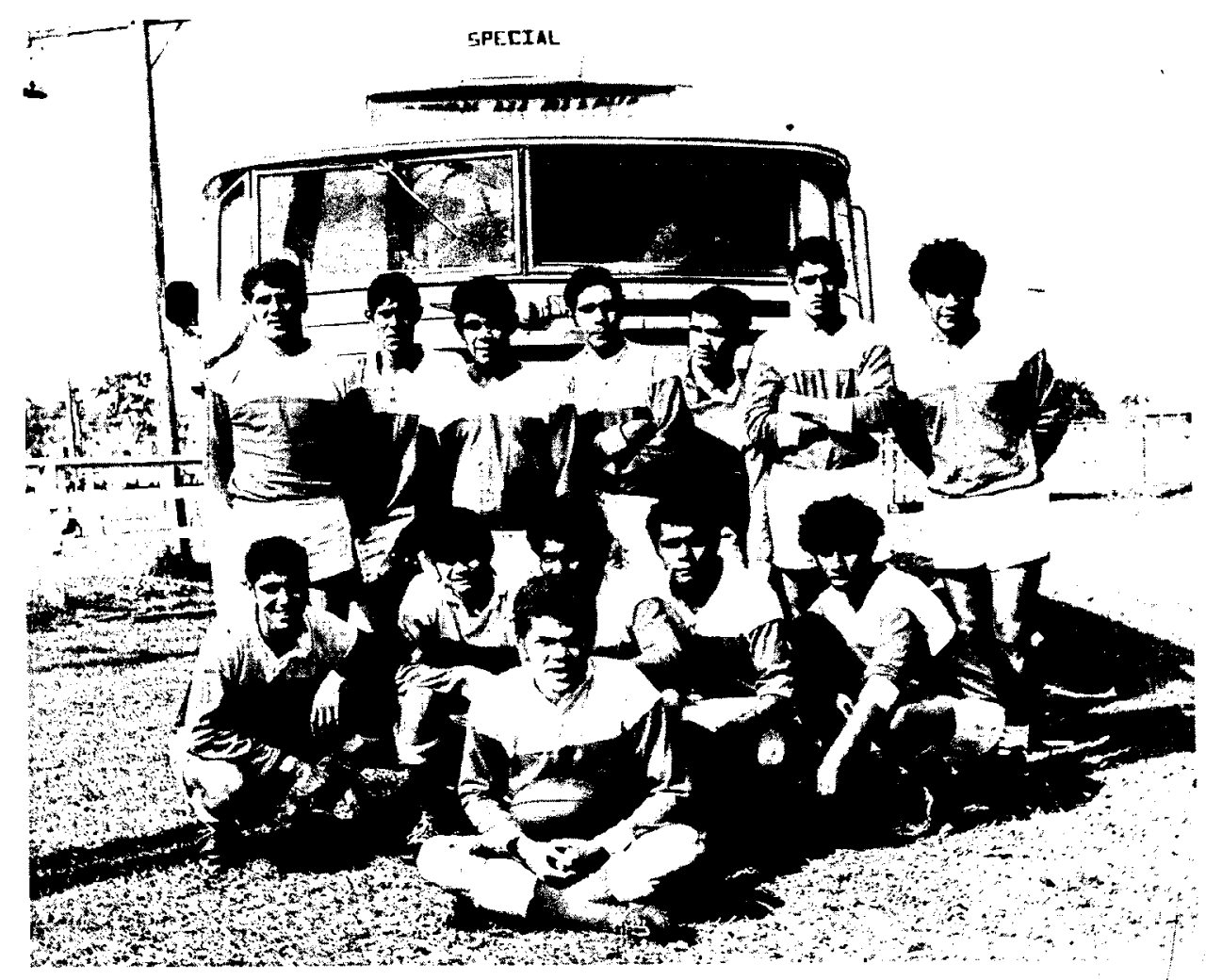

Redfern All Blacks, Casino, 1969. Photo courtesy Andrew Jakubowicz.

Redfern. While their participation in the South Sydney Juniors competition was more continuous from the 1960s and at different times officials contested their participation, $\mathrm{RAB}$ have won the Knockout ten times and on each occasion they have won back-toback. In 2006 they won a historic four years running, along with success in the Souths Juniors district.

The establishment of the Council for Aboriginal Affairs following the 1967 Referendum, among other things, resulted in funding being made available for Aboriginal organisations and events. The Council for Aboriginal Affairs established the Aboriginal Sports Foundation that came to fund some RAB activities, including two tours of New Zealand, dances and NADOC (National Aborigines' Day Observance Committee) activities.

The Council also funded NADOC week events, such as the sponsorship, along with the State Bank, of the prize money for the winners of the regional Knockout in Moree in 1969. ${ }^{17}$ In 1969 RAB travelled to Moree, Casino and Bega to participate in NADOC week regional knockouts. This was covered in New Dawn with a picture of $\mathrm{RAB}$ on the front cover in June 1970, wearing red and white jerseys. ${ }^{18}$

17. Dawn Magazine 1969, 'Report on NADOC week activities in Moree'. 'NADOC' in more recent times is spelt 'NAIDOC' and refers to the national week of celebration of Aboriginal and Torres Strait Islander people and culture, generally held in early July. 
Town -based knockouts continue, although these are largely organised as lead-up competitions for the main Knockout in October. The lead-up Knockouts are often fundraisers and provide a 'practice run' for teams, they include Canberra, Dubbo, Ballina and Blacktown. Most of the teams will travel the distance to attend the lead-up Knockouts. This is evident in the 2005 winners: in Canberra, Walgett BAC won, and the Newcastle Emus took out the Dubbo Knockout.

From the 1970s Aboriginal football teams began organising and competing in country rugby league competitions. For example New Dawn in 1972 featured a picture of the Wilcannia Boomerangs, and reported that they were a 'first grade, all-Aboriginal Rugby League Team ... in the Broken Hill District League Competition', formed in 1970 with the help of a grant from the Office of Aboriginal Affairs. ${ }^{19}$ Similarly, in Armidale the all-Aboriginal NARWAN Eels were formed in 1977 in response to the sense that Aboriginal players weren't getting a 'run' in the Group 5 Country League Association. Mitchell Morris, Colin Ahoy and the late Lance Moran and Catholic priest David Perrett formed the all-Aboriginal NARWAN Eels who went on to win the prestigious country league Caltex Shield and the Clayton's Cup along with five consecutive premierships, as well as the Knockout, in $1980 !^{20}$

The Moree NADOC celebrations in September 1970 hosted a football Knockout carnival and a Ball as well as a basketball competition and performance by the National Black Theatre. New Dawn reported the football competition was won by Moree-based 'Wirajarai [sic] club' who received a $\$ 300$ cheque from the Rural Bank. ${ }^{21}$ Club President, Mr Tommy Cain said the prize money would be donated to the 'Wirajarai P \& C Association' and a smaller amount to the Mission-based Sisters of Charity 'in recognition of their services to Aborigines'. ${ }^{22}$ This example provides some insight into community capacity to organise, an indication of private sponsorship and support, as well as a sense of the changing political environment from Mission to community control. The football carnival can be seen as being in the middle of these developments.

\section{Football and politics}

The football was a vehicle for Aboriginal people to gather and organise in an otherwise authoritarian and controlled environment of restricted movement and association. It is also possible to understand the NADOC celebrations and particularly football competitions, and the social and political interactions that ensued, as impetus for relocations to the city, if only because of the possibility to earn money through football.

Mr Ken Brindle writing in New Dawn in June 1970 confirms this sentiment in saying:

when youngsters first arrive in Sydney, a club consisting of their own people, where they can become involved and feel part of, assists them immensely to settle down in the first crucial ... weeks. ${ }^{23}$

18. New Dawn, June 1970, 1(3): cover. Participants in the research recalled RAB playing in the red and white colours of St George, following sponsorship from the Club.

19. New Dawn, April 1972, 3(1): inside cover.

20. Tatz 1996: 84.

21. New Dawn, September 1970, 1(6): 5 .

22. New Dawn, September 1970, 1(6): 5 . 


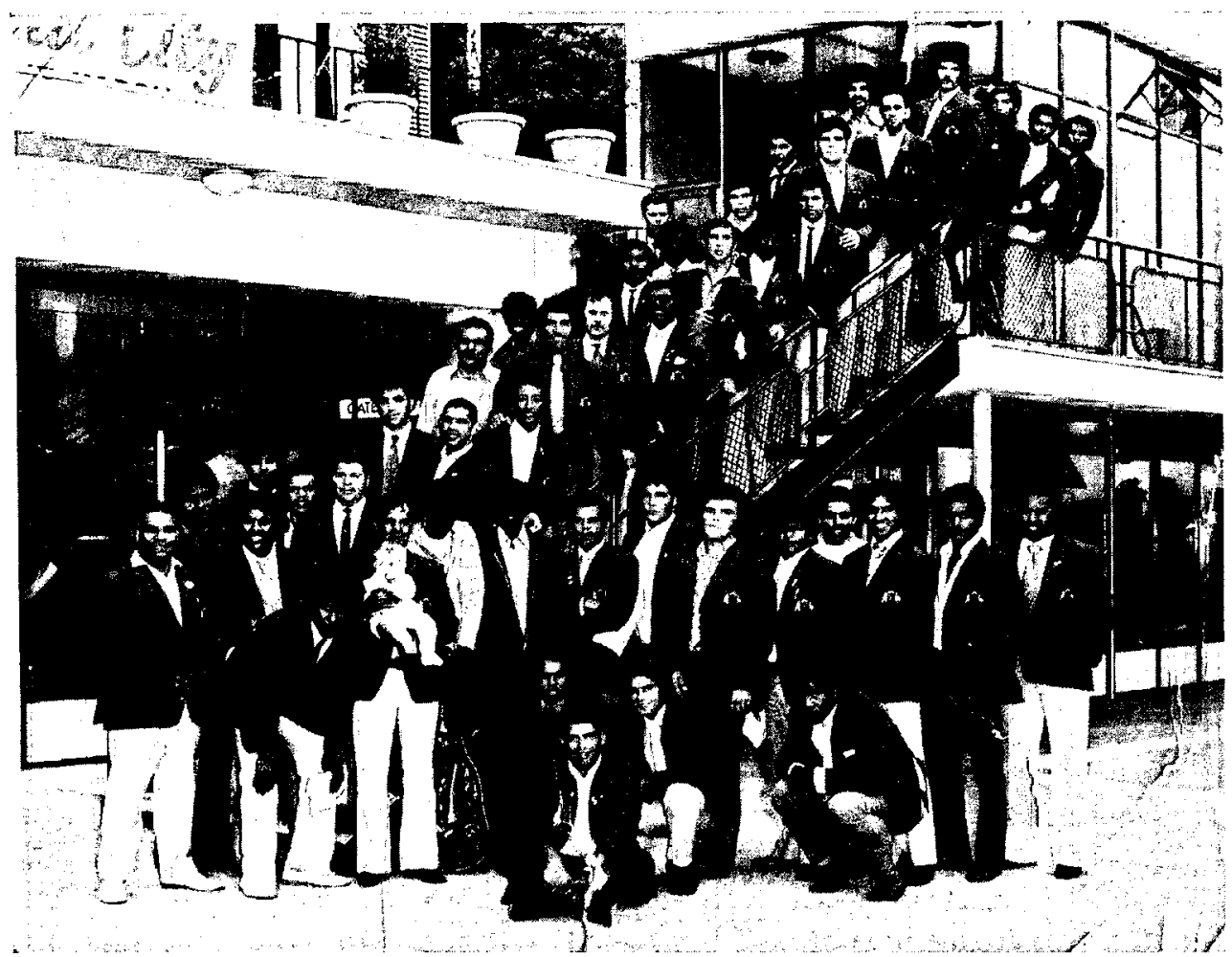

Redfern All Blacks tour to New Zealand 1971. Photo courtesy of the Mason Family

He goes on to say that the club:

affords them good training in management ... and responsibility [and often] become involved in their players problems [and] ... help to find employment, accommodation and quite often legal assistance for minor offences' ${ }^{24}$

RAB held dances and cabarets to finance its activities at the Foundation for Aboriginal Affairs. Bands, such as Max Silva's legendary 'Black Lace' and 'Silver Lining' were regular performers at the Foundation and other venues. Ken Brindle also forged links with other supportive activists groups including the Communist Party of Australia and Australian Aboriginal Fellowship.

Brindle, in acknowledging the National Aboriginal Sports Foundation grant of $\$ 1000$ for the RAB 1971 New Zealand tour, said:

the Commonwealth Office of Aboriginal Affairs does realise the value of Aboriginal participation in sport, ... all the placard waving, demonstrating and demands will not open one tenth of the doors that can be opened through sport. ${ }^{25}$

\footnotetext{
23. New Dawn, June 1970, 1(3): 1 .

24. New Dawn, June 1970, 1(3): 1.

25. New Dawn, June 1970, 1(3): 2 .
} 
Similarly, Ray Vincent with some 60 years of association with RAB said, 'When you think about it, the Blacks have been political since way back when ... without realising they were making a statement, but they were'. He argues that, 'The Blacks are the longest running political organisation that we have'. ${ }^{26}$ In reflecting on RAB, Ray Vincent, said:

Politics is always a part of what we were doing but it was never the driving force. It was more about sport and more about family and more about community. And I think that's the way it's got to be. ${ }^{27}$

Ken Brindle, RAB President, was involved in a range of community activities, including proposals to the Council for Aboriginal Affairs for a community centre. The Council for Aboriginal Affairs in responding to these requests had their own ideas about governing arrangements for the emerging Aboriginal organisations in Redfern and advocated a central body to oversee the Aboriginal Medical Service, Aboriginal Legal Service and RAB. Similarly, Brindle in organising the New Zealand tours, articulated them as cultural exchanges and community development.

The organisation of football teams was a response to a sense of exclusion and desire for greater success in rugby league. The motivation behind the formation of the NARWAN Eels for a 'fair go', along with the Knockout organisers wanting Aboriginal players to 'get noticed' is evidence of this. Ken Brindle saw RAB as a means to build community and cultural capacity and pride. The organisation of football teams carried with them far greater significance - they were vehicles for community development and the re-forming of new communities.

While this can be understood as political activism, a different articulation of politics emerges. It is about assertion of identity and strategic efforts to maintain and build cultural continuity as much as a campaign for rights and justice. It is a more Aboriginal centred account of political activism that expresses culture and family as central to rights and justice.

\section{Kinship and the Knockout}

Further to economic and social context, kinship connections have continually underpinned the way Aboriginal people settled in the urban context of Sydney. Family or kinship connections were reflected in the 'second wave' of migration of Aboriginal people to Sydney and how these relations were maintained and renewed in a changing environment. In the early years, as the inner-city Aboriginal community expanded, and throughout the history of the Knockout, the football teams have formed a central base around which communities have gathered and aligned.

The Knockout as a modern day corroboree continues to be organised along kinship and nation-based affiliations. The teams are clan or family-based and in other cases seek to rebuild, not necessarily along bloodlines, but modelled on patterns of interaction, relationship and connections in new environments.

Koorie United formed in response to new and changing communities. This can largely be understood in terms of the late 1960 s pattern of migration of Aboriginal peo-

26. Interview with $R$ Vincent, conducted by the author, 25 August 2004, Redfern.

27. Interview with $R$ Vincent, conducted by the author, 25 August 2004, Redfern. 
ple to Sydney, particularly Redfern and the inner-city. While older families who migrated to Redfern in the pre-war era were affiliated with RAB and La Perouse was similarly linked with the La Perouse community and South Coast families, Koorie United and $\mathrm{RAB}$ were friendly rivals that reflected different cultural groupings and social and economic experiences.

While the Redfern community is strongly associated with the area known as 'the Block', before the Whitlam Government's handing over of the land to the Aboriginal Housing Company in the early 1970s, Koori families occupied Caroline Street and surrounds. The Vincent family for example shifted from Singleton to Redfern before the Second World War. The Madden, Hinton, Lester, Davidson, Robinson and Lord families also lived in the Caroline Street and surrounds. These older families, that pre-date the 1960 s wave of migration to the inner city strongly identified with $\mathrm{RAB}$, a connection that endures today. The formation of Koorie United can be read as a response to what were already established kin- and community-based affiliations as well as the desire to create means by which new and changing communities could associate and organise, and play football.

To understand the ongoing kin and community-based connections the recent example of RAB is useful. When RAB players entered the 'Cec Patten-Ron Merritt memorial side' in the Knockout in 2003 they combined both the desire to bring their communities and families together and honour those who had made a contribution to the community. Wes Patten and Graham Merritt organised the team to honour their late fathers and the contribution they made to the establishment of the legal service and other organisations and to RAB. ${ }^{28}$ Ron Merritt's wife, Mrs Lorraine Merritt was a Vincent, one of the very early Redfern families living on Caroline Street. Phyllis Patten (who married Cec Patten) and Ron Merritt are cousins. Both Cec Patten and Ron Merritt, with a passion for $R A B$, came to be best friends. We see in this example extended family relations that are both historical in terms of the relationship to Redfern and kin-based.

The Vincent family have a long association with RAB. Ray Vincent recalls being carried out on his father's shoulders at Redfern oval when he was about four years old before World War Two. ${ }^{29} \mathrm{He}$ spoke of his uncles and brothers playing for RAB and now his nephews, including Graham Merritt. For the Vincent family their association spans the history of RAB across four generations. It was reported that there was one small 'hiccup' in this long association. In 1976 Ron Merritt formed the Knockout winning side, the Louis St Dodgers. ${ }^{30}$ Graham Merritt remembers a period of 'no-speak' between his parents as a result of this!

There are many other families who have a similar cross-generational association with RAB. The Madden family for example, introduced a memorial trophy in honour of the late Lee Madden at the 2004 Knockout. Lee's father, Uncle Charles 'Chicka' Madden, along with his brothers and uncles are life members of RAB.

28. Interview with Graham Merritt, conducted by the author, 26 August 2004, University of Technology, Sydney.

29. Interview with Ray Vincent, conducted by the author, 25 August 2004, Redfern.

30. Louis Street is one of the four streets that make up 'the Block'. 
Further to this long-standing kin-based connection, RAB also came to be a home for many Aboriginal people who experienced life in institutions. This was particularly the case for former residents of Kinchela Boys Home (KBH). At the 2002 Knockout the 'Kinchela Boys Home Ken Brindle Memorial Shield' was presented to the most promising player in the grand final. ${ }^{31}$ The shield honoured Ken Brindle's association with RAB and paid tribute to the association of $\mathrm{KBH}$ residences and their special place in the Redfern community. In a very moving ceremony just prior to the grand final, the former residents walked on to the oval and were presented to the crowd as a smoking ritual was carried out. Whilst a very sad moment, the ceremony affirmed the significant relationship to 'place'.

The $\mathrm{RAB}$ memorial side and the presentation of memorial trophies and shields is a tribute to individuals that reflects complex social, political and cultural relations. RAB is in some ways different to other teams in that they are a team with a long history that competes throughout the season while other teams form for the purpose of competing in the Knockout. While RAB competes in the Souths Juniors competition, it is the Knockout where the ceremonies and acknowledgements take place.

David Widders in organising the Armidale team the Echidnas explained his motivation was to bring his family back together. He said that since the passing of his Nan and Pop the family had gone in 'all different directions' with some family members not talking to others. Organising a team and entering the Knockout was a way to get the Widders and extended family reunited. His concern was that, 'we only ever seem to get together for sad reasons, like funerals' ${ }^{32}$ Widders explained that while his involvement with sport has been extensive, getting the Echidnas to the Knockout was the most rewarding experience for him. He also explained that the name, the Echidnas, was his grandfather's totem and the first Knockout game they played coincided with the anniversary of the passing of their Pop. Widders interpreted this as a sign that organising the team was culturally 'right'.

Similarly, for other towns, where the New South Wales Welfare Board force relocated families from distant regions, family-based connections are affirmed through Knockout teams. Large centres like Dubbo are represented by different teams, such as the Pacemakers and Googars, at the Knockout. While from the same town and community the teams draw from different families that in part reflect the history of connection to place and origin. The Googars, competing in the Knockout since 1988, was formed by the late Tom Gordon. In 2000, his family entered the 'Tom Gordon Memorial Team' in the Knockout where his five sons played in his honour. ${ }^{33}$

Danny Thorne was motivated to form the South-West Metropolitan Waratahs in 2002 for different reasons. ${ }^{34}$ Thorne explains, in the absence of a traditional or tribal association in the Campbelltown area, south-west of Sydney, it was appropriate to come up with a team emblem that was representative. He said the Waratah, traditional

31. This award was won by Don Walker playing with Mulli Mulli in 2002

32. Interview with D Widders, conducted by the author, April 2005, University of Technology, Sydney.

33. Daily Liberal, 'Brothers honour dad: Gordon boys aiming for knockout carnival win', 29 September 2000: 42 .

34. Interview with D Thorne, conducted by the author, August 2004, Campbelltown. 
to the area and the New South Wales floral emblem, captured the whole Aboriginal community. He formed the team to build a greater sense of community and to support younger players with their identity. He suggests the Knockout is an opportunity for young players to meet their extended families which is significant as many younger members of the community seem lost to their identity and culture and sometimes, he says, 'where you are second generation born in the city, you can lost those contacts with your country'. ${ }^{35}$ Thorne set out to build a sense of community and connection in Campbelltown and south-west Sydney amongst Aboriginal people. Thorne also experienced the move to the city from Walgett and played with Koorie United.

This sentiment was reiterated by Barry Duncan regarding the team he founded in 1997, the Central Coast Pelicans. ${ }^{36}$ Duncan explained that he felt the Central Coast community were struggling with a sense of identity. While they were on Darkinjung land the community consisted of members from all over New South Wales and elsewhere without a traditional base or connection to country. While they were a 'community' when it came to Land Council and other business, for the Knockout most who had relocated to the coast barracked with their 'home' communities. Putting a side in the Knockout was a means by which the Central Coast community could become united and also address the very specific issues for the central coast community, such as the very high incidence of youth suicide.

These examples can be seen to be clan- or family-based and in other cases seek to rebuild, on this pattern of interaction, relationships and connections in new environments. This exemplifies the richness and inter-connectedness of contemporary Aboriginal lives that continues to be kinship-based and modelled on kin or family systems of organisation. The organisation of football teams for the Knockout reflects Aboriginal aspirations for family and community that are both traditional and responsive to economic change and its social effects, and to Government policy. This includes relocation to urban centres for work as industries changed, and areas such as the central coast and greater Sydney came to be centres for relocation. Government policies, such as the concentration in reserves and integration through housing and urban relocation. These are matched by Aboriginal people seeking to maintain and renew community affiliations.

\section{The political economy of the Knockout}

This final section turns to the political economy of the Knockout. The Knockout is an example of entrepreneurial and organisational skill and community capacity. It attracts thousands of Aboriginal people. Over the last few years there have been from 45 to 60 teams competing. Each team comprises 25 players plus coach, trainers and officials. This alone makes up 2000 or more participants. There are no official records of crowds or gate takings and estimates vary considerably. There were between 12,000 and 18,000 spectators over the four days. During the long weekend in October 2004, in the evenings of the Knockout weekend, every pub and club in Redfern and surrounds was packed to capacity with most closing their doors, including Souths Leagues Club. For this research project, it has been a difficult task to gather economic data to estimate the

35. Interview with D Thorne, conducted by the author, August 2004, Campbelltown.

36. Interview with Barry Duncan, conducted by the author, April 2005, Redfern. 
economics of the Knockout where businesses have been reluctant to disclose information about their takings for the long weekend. However, Warren Mundine, former Dubbo Councillor, reported that the Dubbo Chamber of Commerce calculated the economic contribution of the Knockout for Dubbo in 1999 to be $\$ 4$ million. ${ }^{37}$ The Nambucca Valley Chamber of Commerce, Eunice Peachey President of the Pacemakers and others also referred to this figure of $\$ 4$ million. The Honorable Member Jan Burnswood said in Parliament that, "It was the most successful carnival ever held and in 1999 more than $\$ 4$ million was brought into the Dubbo economy through accommodation, hospitality et cetera'. ${ }^{38}$

Both Nambucca and Dubbo Chambers of Commerce said it was standard in estimating the economics of an event to calculate $\$ 200$ per person. It is reasonable to suggest that the actual figure could be more than this estimate given the entertainment associated with each evening of the Knockout. If the calculation is based on a figure of $\$ 250$ per head per day and the overall crowd is conservatively estimated at 13,500 , the Knockout can be estimated to generate approximately $\$ 3.4$ million for a host town.

The Dubbo Pacemakers and Wellington Wedgetails combined organising committee for the 1999 Knockout estimated that the expenditure for the event amounted to approximately $\$ 300,000$. The committee made a profit of $\$ 30,000$ that was channelled back into the community for employment, health and sporting venues. ${ }^{39}$ The Redfern All Blacks organising committee for the 2004 Knockout also said that "before a ball had even been kicked', the organising committee required a starting budget of $\$ 200,000.40$ The organising committee were meeting every week at Souths Leagues Club from November 2003. As the Knockout drew closer the committee met daily. Ricky Lyons, Committee Secretary said, 'organising the Knockout basically has taken over my life'. Graham Merrit of the RAB organising committee, referred to the organising of the Knockout as 'a big headache'. The organising committees of the Knockout meet and negotiate with a whole array of Government and agencies, including Local Councils and their various committees, police, ambulance and roads and traffic control.

The report by the New South Wales Annual Rugby League Association (NARLA) of the Knockout in Armidale gives some indication of both the level of organisational complexity and expenditure associated with hosting the Knockout. The package for the NARLA Knockout, distributed amongst delegates, features colour photos of fields, accommodation directory, lists of all tasks, operating budget: just about every detail from grounds hire to footballs, clocks and hooters. This document provides insight to the level of organisational skill involved in staging a competition with so many participants, at an unprepared venue with such large crowds. The NARLA Knockout in Armidale employed a co-ordinator for 14 weeks in the lead-up to the Knockout while the Bourke Local Council employed a consultant to assist with the organisation of the

37. Interview with W Mundine, conducted by the author, August 2004, Office of the NSW Native Title Service, Redfern, New South Wales.

38. The Hon. Jan Burnswood, NSW Legislative Council Hansard, 5 April 2000: 4147.

39. The Hon. Jan Burnswood, NSW Legislative Council Hansard, 5 April 2000: 4147.

40. This was reported by two interview participants and committee members, Ricky Lyons (25 August 04) and Graham Merritt (August 2004), and at the meeting of the organising committee (26 April 2005). 
Knockout when they hosted it in 1996. However, the Knockout is run by a committee of volunteers and many hundreds of volunteers carrying out related tasks.

The Knockout is an enormous event to organise with most communities starting this process from scratch. There is no template or guide on 'how to organise the Knockout', in many cases there are those who have been involved in organising Knockouts before who lend support and expertise. Committees book the grounds, prepare the grounds such as line-marking, emblem stamping, recruit referees and line's men, clean the grounds, provision of toilets, cleaning of toilets, in some cases the construction of amenities, transport between fields, security, footballs, football pumps, clocks, hooters, tables, chairs, tents for elders, marquess for different communities and public liability.

It is not hard to imagine the revenue generated over the course of the long weekend as a result of Knockout visitors. Imagine this kind of economic activity in small country towns-like Walgett with two motels, one supermarket and four pubs and clubs. In other towns Armidale, Dubbo and Maitland it was reported in the local media that all accommodation was fully booked over the long weekend as a result of the Knockout. However, despite the financial injection into regional economies, in some instances the holding of the Knockout has been opposed by the business community. This was the case in Nambucca Heads where the local business community spoke against the hosting of the Knockout in letters to the local paper and local council. They claimed health and safety concerns.

The Knockout cannot be measured in terms of economic contributions to the local business and towns alone. When Barwon Aboriginal Corporation (BAC), Walgett, hosted the Knockout in 1989, the club built an amenities block including change rooms and showers for players at the Oval. BAC also installed lights and built a grandstand. The economic contribution can therefore also be seen in terms of significant infrastructure. The facilities that BAC built, largely by volunteers, were assets for the whole community to use.

In addition, there is significant employment generated for the duration of the weekend. Many of the pubs and clubs recruit local Aboriginal people to work behind the bar and as security, there are also staff on the grounds, including the gates, security, food stalls, Government services and promotion stalls.

Each team that participates raises a significant amount of money to fund their Knockout campaign. The non-refundable entry fee for each team in 2004 was $\$ 2000$. On top of this each team completely outfits their players, team officials and supporters. Most players and officials would be equipped with jerseys, shorts, socks at the minimum and more likely, drink bottles, caps, carry bag and casual clothes for evening wear along with supporters caps and T-shirts. All of these would normally be dated with the name of the side, year and location of the Knockout. The basic outfit of jersey, shorts and socks was valued, as a special deal for the Knockout team, as \$3,000.

Danny Thorne, President of the Waratahs, estimated that they would need about $\$ 30,000$ to compete in the Knockout. This covers accommodation, registration, food and drink for players and marquee for their supporters for the weekend and bus. For the last three years the Waratahs have been sponsored by developers Mirvac. The Armidale Echidnas raised $\$ 20,000$ to fund their campaign to Sydney in 2001 . This included accommodation, hiring of a bus, players and supporters gear. For South West Metro 
their costs are significantly less than for teams who travel from Bourke and Moree where whole teams and community require transport and accommodation.

The Moree Boomerangs for the 2001 Knockout campaign were sponsored by Joblink, The Aboriginal Employment Strategy, Rolf's Fuel and Exhaust, Raylen's Café, Brighann Ginning, Irritek, Moree Hotel, Elco Australia, Bignall's Tender Meats, Moree Freight Service, Lowrey's Small Motors, Kenway and Clark and Moree Place Management. ${ }^{41}$ The Moree Shamrock Warriors fundraised with raffles and a small amount of sponsorship from Tjapiya Security and Sullivan's Newsagency. These sponsorships indicate considerable resourcefulness and credibility amongst the Aboriginal community along with goodwill from the business community.

\section{Conclusion}

The Knockout has been an enormously successful and significant event that is passionately embraced by the New South Wales Aboriginal community. The Knockout emerged in the context of considerable social, economic, cultural and political change. It is a vehicle for the continuation and regeneration of cultural traditions. It has been the means by which new communities are forged, where love is realised and stars made. For others it is the way to reconnect and celebrate being Aboriginal in an all-Aboriginal celebratory and successful environment. This success is in terms of survival, sporting success and the very ability to convene such a large event. This study shows how Aboriginal aspirations have responded to economic change and its social effects, and to government policy. This paper has demonstrated the centrality of the Knockout as an affirmation of culture, identity and community or clan-based affiliations.

\section{Acknowledgements}

Research on the Knockout was made possible by a grant from AIATSIS and Jumbunna Indigenous House of Learning at the University of Technology, Sydney. The author wishes to thank Professor Gillian Cowlishaw, Associate Professor Heather Goodall, Dr Bob Morgan, Cameron Muir and Sonny Edwards for comments on this draft and research support.

\section{References}

\section{Newspapers and unpublished sources}

Daily Liberal

Dawn Magazine

Moree Champion

New Dawn

NSW Annual Aboriginal Football Knockout, 1995 Host team Toomelah Tigers Rugby League Football Club, 28, 29, 30 September and 1, 2 October 1995, Official Program 1995.

NSW Annual Rugby League Association (NARLA), Apex Oval, Dubbo, hosted by the Wellington Wedgetails, Official Draw, 1999.

NSW Aboriginal League Knockout, Armidale, Information for Delegates, 2001.

41. Moree Champion, 27 September 2001: 28. 
NSW Legislative Council Hansard, The Hon. Jan Burnswood, 5 April 2000: 41-47.

Sydney Morning Herald

\section{Published sources}

Baker, J, 2005, 'Cowboys or Tigers, theyre riding on black pride', Sydney Morning Herald, October 12: 7.

Brindle, K 1970, 'A club to be proud of ...', New Dawn, 1(3) June: 14.

Cowlishaw, G 2004, Blackfellas, whitefellas, and the hidden injuries of race, Blackwell Publishing, Carlton, Victoria.

Goodall, H 1995, 'New South Wales', in A McGrath (ed), Contested ground: Australian Aborigines under the British Crown, Allen and Unwin, St Leonards, NSW.

- 1996, Invasion to embassy: land in Aboriginal politics in New South Wales, 1770-1972, Allen and Unwin, St Leonards, NSW.

Hartley, J 2002, 'Black, white ... and red? The Redfern All Blacks Rugby League Club in the early 1960s', Labour History, 83(November): 149-171.

New Dawn, 'A Moree NADOC triumph', September 1970, 1(6): 27.

Nugent, M 2005, Botany Bay: where histories meet, Allen \& Unwin, Crows Nest, NSW.

Reynolds, H (ed) 1972, Aborigines and settlers: the Australian experience, 1788-1939, Cassell Australia, Stanmore, NSW.

- 1989, Dispossession: black Australians and white invaders, Allen and Unwin, Sydney.

— 1995, Fate of a free people, Penguin, Ringwood, Victoria.

Tatz, C 1995, Obstacle race: Aborigines in sport, New South Wales University Press, Kensington.

\section{Interviews}

Interview with H Donovan, conducted by the author, August 2004, Redfern.

Interview with Barry Duncan, conducted by the author, April 2005, Redfern.

Interview with R Lyons, conducted by the author, 25 August 2004, Offices of the

Department of Sport and Recreation.

Interview with Graham Merritt, conducted by the author, 26 August 2004, University of Technology, Sydney.

Interview with J Miller, conducted by the author, 31 August 2004, Powerhouse Museum.

Interview with B Morgan, conducted by the author, 30 May 2004, The Entrance, Central Coast.

Interview with W Mundine, conducted by the author, August 2004, Office of the NSW Native Title Service, Redfern.

Interview with B Smith, conducted by the author, 19 September 2004, Offices of the Department of Education, Kempsey.

Interview with D Thorne, conducted by the author, August 2004, Campbelltown.

Interview with R Vincent, conducted by the author, 25 August 2004, Redfern

Interview with D Widders, conducted by the author, April 2005, University of

Technology, Sydney. 